April 2019

\title{
Lecturers learning to teach: the role of agency
}

Mary Omingo

Aga Khan University, omingo.mary@aku.edu

Follow this and additional works at: https://ecommons.aku.edu/eastafrica_fhs_fhs

\section{Recommended Citation}

Omingo, M. (2019). Lecturers learning to teach: the role of agency. International Journal for Academic Development, 24(2), $122-134$. Available at: https://ecommons.aku.edu/eastafrica_fhs_fhs/16 


\section{International Journal for Academic Development}

\section{Lecturers learning to teach: the role of agency}

\section{Mary Omingo}

To cite this article: Mary Omingo (2019) Lecturers learning to teach: the role of agency, International Journal for Academic Development, 24:2, 122-134, DOI: 10.1080/1360144X.2019.1595627

To link to this article: https://doi.org/10.1080/1360144X.2019.1595627

曲 Published online: 08 Apr 2019.

Submit your article to this journal $\widetilde{ }$

LII Article views: 34

View Crossmark data \lceil 


\title{
Lecturers learning to teach: the role of agency
}

\author{
Mary Omingo \\ Teaching and Learning Network, The Aga Khan University, Karachi, Pakistan
}

\begin{abstract}
Lecturers may be exposed to the same Academic Development Programme but their course of action at personal and professional level vary. In this paper, I analyze the lecturers' contribution in shaping their learning to teach. I interviewed twenty-five lecturers in four private universities in Kenya using semi-structured interviews. The analysis showed that the onus to learn how to teach lies with the individual lecturer (agency) especially in contexts that lack a systematic approach to lecturers' learning. Academic developers may be interested in understanding how the exercise of agency in learning how to teach leads to variations in lecturers' actions.
\end{abstract}

\section{ARTICLE HISTORY}

Received 5 October 2018

Accepted 12 March 2019

\section{KEYWORDS}

Agency; contribution; Kenya; learning to teach

\section{Introduction}

Studies on how lecturers learn to teach tend to concentrate on formal and informal learning. Roxå and Mårtensson (2015) focus on lecturers' informal learning in micro cultures that influence the interactions between formal and informal learning in day-to-day practices. Rienties and Hosein (2015) note that lecturers find workplaces significant outlets to share their feelings, challenges, and frustrations about teaching. Vorster and Quinn (2012, p. 57) show that academic development programmes (ADPs) tend to disrupt lecturers' 'common sense of understanding about teaching and encourage them to critically reflect on the teaching processes'. According to Quinn (2012), ADPs and workplace environment, such as the culture of a department, may enable or constrain lecturers' learning.

Whereas Kahn (2009a) looks at the exercise of agency in early career academics and Clegg (2005) notes the need to pay attention to the exercise of agency at micro level in policy issues, little attention is given to the role lecturers' agency plays in their learning to teach. The exercise of agency is what mediates between the ADPs and lecturers' concerns. Once lecturers prioritize their concerns, they then identify courses of action that transform practice. Archer (1995, p. 257; 2003, p. 118) defines agents as 'collectivities sharing the same life-chances, [that] do have interests (in improving or protecting the latter) which are external to the roles yet can be pursued through them'. In learning how to teach, lecturers are agents of change in their personal and professional growth, and student learning. We need to consider the exercise of agency by lecturers, mainly intentionality and reflexive deliberations as discussed by Archer (1995) as it is significant in their learning to teach. The exercise of agency mediates the contexts (ADPs and workplaces) in which lecturers learn how to teach and the concerns they hold. Lecturers' courses of action that lead to practices are grounded in their concerns. In this 
paper, I analyze lecturers' contribution in shaping their learning to teach by answering the question Elder-Vass (2010, p. 87) posed: 'What is it about human beings that gives them the power to act?'

\section{Intentionality, reflexivity and concerns}

According to Archer (2000), social interaction is the sole mechanism that governs stability or change in the structural world, and through personal emergent powers of reflexivity and intentionality human beings forge their way in the world.

\section{Reflexivity and concerns}

Reflexivity is 'the regular exercise of mental ability shared by all normal people, to consider themselves in relation to their (social) contexts and vice versa' (Archer, 2003, p. 4), and is a means by which we make our way through the social world. It involves such patterns of internal conversation as 'mulling over', 'rehearsing', 'imagining', 'reliving', and 'prioritizing' (Archer, 2010). As such, reflexive deliberation provides a basis on which an individual determines future courses of action in relation to objective circumstances (Archer, 2003).

Archer (2007) identifies four varied modes of reflexivity: communicative, autonomous, meta-reflexive, and fractured reflexives. Communicative reflexivity entails 'thought and talk' (Archer, 2007, p. 93): the internal conversation is completed and confirmed by external dialogue with others prior to a course of action being initiated. Autonomous reflexive types do not consult others; their internal conversations lead directly to action. Meta-fractured reflexives, on the other hand, are critically reflexive about their internal conversation and critical about effective action in society. For fractured reflexives, their internal conversation does not lead to any action due to distress and disorientation. Archer (2007, p. 5) asserts that the reasons for promoting reflexivity to a central position within the social theory is that 'the subjective powers of reflexivity mediate the role that objective structural and cultural powers play in influencing social action' and are thus indispensable to explaining social outcomes. She further suggests that to understand why people act at all and what motivates them, it is necessary to examine their personal concerns and inner reflexive deliberations.

Human beings have ultimate concerns and through reflexive deliberation they prioritize their concerns in the three orders of reality, namely: physical well-being in the natural order, self-worth in the social order, and performative achievement in the physical order (Archer, 2000). The process of reflexively prioritizing concerns leads to the development of personal identity. For instance, some lecturers' priority may be physical well-being and for others it may be self-worth. Archer (2003, p. 140) affirms that an ultimate concern which has been reflexively defined brings about change: 'it acts as a prism which refracts the exercise of objective enablements and constraints'.

\section{Intentionality}

One of the most important differentiating powers proper to people is their intentionality: 'their capacity to entertain projects and design strategies to accomplish them' (which may or may not be successful) (Archer, 1995, p. 198). Knight, Tait, and Yorke (2006) link 
intentionality with structuring of the learning processes and note that intentional formal learning relates to learning opportunities which are structured (follow a curriculum) for learners while intentional informal learning relates to learning opportunities that are not planned for learners (engage in reflection). However, behind these processes are people who intentionally attend the ADPs and actively participate in the discussions and practice self-reflection. Archer therefore adds more value when she looks at intentionality as stated above. The ascription of intentionality to learners shows how important the role of learners, lecturers in this study, is in shaping their own learning trajectory.

\section{Methodology}

I applied both exploratory and explanatory research strategies. An exploratory study was deemed the most appropriate in resolving the research problem: lecturers' contribution in shaping their learning to teach. An exploratory study was also appropriate since lecturers' contributions are diverse. Additionally, the study was explanatory as the research question 'how does lecturers' agency shape their learning to teach?' - required explanations about the causation. Sayer (2010, p. 105) explains causation, not as the number of times that something happens but as 'explanation that depends on identifying causal mechanisms and how they work, and discovering if they have been activated under what conditions.' In this paper, causal mechanisms that make lecturers act at all are analyzed.

I used purposive, snowballing, and random sampling to identify twenty-five lecturers from four private universities in Kenya that had initiated some form of ADPs. The data collection methods I used were semi-structured interviews and observations. The interviews were appropriate as they allowed the lecturers to convey opinions, experiences, their own understanding of what they experienced, and valued accounts of the roles they played in their learning. The interviews provided an opportunity to probe the interviewees' responses for more explanation, to build on and get clarification on some issues that were unclear. I also collected data from classroom observations of six lectures. The observations were mainly used as a follow-up on some of the interviews to corroborate what the respondents had reported during the interviews, but more importantly to gain information about different aspects of lecturers' learning. I was able to observe students' participation, lecturers' facilitation, and the different environments in which students' learning takes place and how lecturers learn from students and the learning environments they create in class. Whilst interviews provided an insight into how lecturers contribute to shaping their formal and informal learning, situations to which I could not gain observational access, observations were particularly important for getting to learn the theory-in-use (Maxwell, 2013).

I used content analysis to analyze data. According to Julien (2008, p. 120), content analysis is 'an intellectual process of categorizing qualitative textual data into clusters of similar entities or conceptual categories to identify consistent patterns and relationships between variables or themes. I first transcribed the video-taped interviews and imported them into Atlas.ti., a software that is user friendly with different types of primary data format. I read through all the transcriptions line by line and paragraph by paragraph, thinking and reflecting on what each was describing. I coded the transcriptions and analyzed the data further using tables, bar charts, network views, reports, and memos into sub-categories and categories. 


\section{The individual's role in learning to teach}

Individual lecturers have a role to play in learning how to teach. The responsibility of the individual in learning how to teach was evident in the following comment:

your contribution to the learning whether you are reading, whatever you are doing, is one little segment. But when you bring in students that adds to the segment, when you bring in external material, published articles, videos about teaching, that is another segment, you bring in an observer that is another segment, when you listen to other lecturers as well that is another segment and for me I think all these things have worked towards helping me learn how to teach better. (Jebu)

The respondent emphasized the individual's role in learning to teach by the use of the second person pronouns 'your' and 'you', that is, the onus to learn to teach lies with the individual lecturer. Similarly, Clegg (2005, p. 153) emphasizes the contribution of an individual lecturer in higher education by stating that:

If we want to theorize about change in education we need a theory that can account for the selves who make choices as academic workers and students, how we engage in constant internal and social debate about conditions of practice, and how we should act to resist, restructure and preserve aspects of the complex system called higher education.

The first role that lecturers play is that of aggregating the various 'segments' that make up their learning that include: learning from facilitators and other participants in workshops and seminars, and from students, colleagues, and industry in their workplaces.

The second role is to decide on whether to attend, or not, the ADPs. A comment from one of the respondents showed that attendance was at the lecturers' discretion: 'in our institution, the director of the Centre of Excellence in Teaching and Learning (CETL) has been trying to organize those peer forums and the only people who attend are those who know the value' (Sey). Although there was support at the institutions, the decision to attend was at the lecturers' discretion.

Another comment illustrated that the respondents had to participate in discussions: 'This semester we have introduced TED talks. That is over lunch hour, once a week, we meet, watch and then discuss and there is an input coming from individuals' (Theo).

Although objective structures such as CETLs impinge on the situations, which the lecturers confront involuntarily by enabling their learning, they require the intelligent co-operation of the lecturers (Archer, 2003). In the above cases, the lecturers' decision to attend and actively participate in the discussions was essential to the functioning of CETLs.

The analysis also showed that the lecturers' role in shaping their informal learning may require an individual's initiative: 'After ADP and from the workshops I started doing my own research, borrowing books from the CETL and reading and then I started experimenting' (Sey). A strong individual drive is necessary to enable one to continue learning in the workplace.

Lecturers in this study also identified themselves with the different teaching approaches they had adopted. It was up to the individual lecturer to choose an approach that he or she was most comfortable with and one that was suitable for his 
or her subject. A comment from a lecturer showed that she decided on using reflective practice as a teaching approach and that involved will and passion:

So I realized that there was need to become passionate and push these issues of reflecting; listening to your own thoughts and trying to interpret them and seeing the meaning of them and all that and so I picked that mode of teaching. (Eca)

The comment is illustrative of lecturers choosing teaching approaches that they are most comfortable with. They establish what Archer (2000, p. 220) refers to as a modus vivendi; or 'a way of life' (Kahn, 2009b, p. 263). Academic developers may want to assist lecturers to determine beforehand modus vivendi instead of facilitating one-size-fits-all ADPs. Beneath such decisions as whether to attend or not, or the teaching approach to apply, are personal emergent powers (agency) that make lecturers act the way they did. Archer (1995, 2000, 2003, 2007) enumerates reflexivity, intentionality, selfconsciousness, self-monitoring, self-commitment, personal identity, and social identity as examples of personal emergent properties. In this paper, I analyze and discuss intentionality and reflexivity as the main personal emergent powers that may bring about variations in the way lecturers act.

\section{Intentionality}

Elder-Vass (2010, p. 87) posed the question: 'What is it about human beings that gives us the power to act?' In my study, it was evident that lecturers learn to teach because they have reasons for doing so. Some are interested in student development and others their personal and/or professional growth. Archer (1995, p. 198) asserts that one of the most important differentiating powers proper to people is their intentionality. Respondents expressed the concept of intentionality in various ways. One indicated that to learn, one had to be intentional since learning is found 'everywhere.'

Do you know that since I learnt and I continue to learn that I don't have to be an authority, but that there is so much to learn ... I realize that lessons are everywhere but learning how to learn is the problem. (Eca)

Another respondent expressed the reason for being intentional as: 'I have learnt to go for things rather than wait for them to fall on my head' (Nep). In the above comments, the lecturers seem to have been expressing intentionality as crucial in their pursuit to grow as lecturers. As earlier stated, where attending the ADPs is at the lecturers' discretion, they intentionally choose to attend and actively participate in the ADPs. One lecturer pointed out that although most lecturers had no intention of attending ADPs, he intentionally attended:

Even the way we came to PCAP, the person organising sent an email "those who want to join training." I just sent an email back for my name to be included. I realised most people here aren't interested in such things, so I said, "let me go and attend". (Kahe)

Academic developers need to realize that lecturers' personal emergent power of intentionality plays a big role especially where there is lack of a systematic approach. According to Bhaskar (1998), intentionality is what demarcates agency from structure. Behind such an act as attending an ADP there is a reason for the lecturer to attend, and 
to go further and actively participate there is a bigger reason to do so. Bhaskar (1998, p. 90) cited in (Archer, 1995, p. 153) states that intentional human behaviour is caused, and ... it is always caused by reasons, and ... it is only because it is caused by reasons that it is properly characterized as intentional.'

\section{Reflexivity}

Internal conversations or reflexive deliberations are also significant in lecturers' learning to teach. Most of the respondents indicated that they deliberated upon their concerns to come up with various courses of action and learnt in the process. One noted that after every class, he deliberated alone on what had gone wrong in the classroom and literally talked to himself about his desire to do better:

In essence I would go back and do reflective learning and say, "I would never do that again" without talking to anyone or reading any book. I would say I want to do it better next time. So that is how I have changed my learning over the years in terms of teaching or improving it. (Daw)

Musholt (2013, p. 649) explains 'I' thoughts as being about self-consciousness. 'I' thoughts are thoughts with first person content that non-accidentally refer to oneself. Further, Musholt (2013, p. 670) asserts that 'the continuous sense of self is also immune to error through misidentification due to the fact that it is necessarily information about the person.' The above mentioned comment shows that the lecturer was concerned about improving students' learning. He tended to learn through internal conversations. Archer (2003) argues that it is possible to be subject and object through inner conversation by formulating our thoughts and then inspecting and responding to these utterances as subject to object.

Another comment showed that the lecturer deliberated on the challenges of teaching her subject:

Research Methods is very challenging. I have thought and thought and thought why it is such a difficult course, everybody complains. No matter how well students are taught, no matter who the lecturer is in Research Methods, when the students come to do their projects in fourth year there are always problems. I thought and even when I went to the Graduate School, I found the graduate students experience the same thing. (Raka)

The comments above show that sometimes lecturers are confident in relying upon their own mental resources. This is what Archer (2007, p. 94) refers to as autonomous reflexivity, that is, a situation where consultations do not take place. In the above cases, both respondents were confronted with the challenge of teaching their subject. Whereas the first one stated how he learned, the second comment implies that no learning may have taken place. Some lecturers may be concerned about students' learning but without the concern culminating into a specific course of action. In such instances, the challenge of teaching the subject is likely to persist because the concern is misplaced. It is also possible that the kind of reflexivity may be what Archer (2007, p. 93) refers to as 'fractured reflexivity'. This is a situation where one engages in deliberation that intensifies personal distress rather than resulting in purposeful courses of action (Kahn, 2009a). According to Kahn (2009a), someone who waits for events to 
unfold rather than seeks to shape those events is characteristically the case for fractured reflexives. Such a person may be less likely to learn to teach.

Furthermore, some lecturers engaged in communicative reflexivity to mediate the role of socio-cultural factors. One lecturer expressed communicative reflexivity as: 'sometimes that talking to a friend is what makes a bulb to tick or some switch to come on' (Jebu). A comment from another lecturer showed that, at first, she deliberated on the students' reaction in class without consulting (she had picked on two students to find out how they were doing and none of them responded) but later consulted colleagues about the same before embarking on learning about the students' culture:

I thought a lot about that experience and realised that there are many issues here that I don't know about e.g. cultural and which I need to learn about to be able to reach out to the students. (Neth)

Through consultations with colleagues she was able to learn about the students' culture and what was affecting her teaching negatively:

Informally I could ask colleagues and friends, "Why did this kind of reaction happen if I am going with an innocent intent?" So people began to explain to me what the education system is like in Kenya. Little by little, I began to realise that in general the whole educational context and background of many of the students is very different from my own experience of my learning, as a child, in the university etc. It was a whole new opening up of my awareness of the diversity that existed between myself and my students. (Neth)

The lecturer was interested in learning more about the socio-cultural factors that affected her interaction with her students. Her concern was the effect the interaction had on student learning. In this case, the influence of the educational and cultural factors on her concern about students' performance was mediated by communicative reflexivity.

Another comment from the same lecturer demonstrated she reflexively deliberated on her values and she eventually dedicated herself to living her educational values with her students:

After teaching three semesters, I realised there is still something here which I am not getting to the bottom of in terms of understanding where my students are at, to be more effective in my teaching. Along with that, I began to realise as I thought more about it and as I became more interested in the 'Living Theory' and in trying to identify what really are my education values. (Neth)

Meta-reflexives are 'those who are critically reflexive about their own internal conversations and critical about effective action in society' (Archer, 2007, p. 93). Some lecturers tend to be critical about their teaching until they get to a point where they develop a teaching approach that they feel they can live with. Archer (2007) asserts that it is important to promote reflexivity. In the case of lecturers, for instance, the subjective powers of reflexivity mediate the role that socio-cultural factors play in influencing the lecturers' courses of action that result in various practices. The interactions in ADPs and the interactions thereafter in the workplaces may result in stable relationships appropriate for communicative reflexivity. Lecturers may also end up being critical about themselves and settle on a modus vivendi that serves society. Furthermore, 
through internal conversation, lecturers may achieve personal identity and/or conceive courses of action dependent on the concerns that they hold for themselves and students' learning.

\section{Lecturers' concerns}

In this study, the concerns that lecturers held tended to shape their agency. According to Archer (2000), the concerns in the three orders of reality: natural, practical, and social are physical well-being, performative achievement, and self-worth. The ultimate concern is what gives people their strict identity as particular persons - their personal identity and social identity.

\section{Physical well-being as a concern}

Evidence in this study suggested that encounters with students, teaching large classes, and learning about university policy statements were some of the significant events or critical incidents that elicited emotions in lecturers. Archer (2000, p. 195) defines emotions as 'commentaries upon our concerns' that are elicited by significant events. She states that 'emotion fosters our commitments, it does not determine them' (Archer, 2000 , p. 241). Events are significant when they touch upon one or more concerns of the subject (Archer, 2000). In this study, lecturers were emotional about students' learning. Emotions such as curiosity, worry, and happiness or joy seemed to have played a role in their learning to teach.

At classroom level, the encounter with students of different educational and cultural backgrounds prompted and challenged lecturers to learn to teach. However, it was emotions like curiosity or fascination, joy or disappointment that prompted lecturers to action. A comment from one lecturer showed that curiosity elicited by students' action of providing more than adequate responses in relation to the lecturer's questions was a prompt: 'Now I am going to start a reflective journal with this group because they have taught me, they are much more serious, they fascinate me a lot' (Luma). This relates to what Archer explains about the effect of congruence and incongruence between people's expectation and experience. In situations where lecturers' expectations and experience were incongruent, like in the above quote, they tend to learn as 'the high intensity end of emotion is activated' (Archer, 2000, p. 207).

At faculty or departmental level, the need to simplify complex ideas, for example in a mathematics class prompted and challenged lecturers to learn to teach. However, it was the emotion of hope on the part of the lecturer, elicited by students' negative attitude towards the subject that prompted the lecturer to learn. He stated, 'I want to see someone change. I want to see that the negative attitude has changed' (Kahe).

At institutional level, established evaluative standards such as students' rating of courses also elicited emotions. According to Archer (2000, p. 218), 'well established standards are evaluative standards, but their effect is dependent upon our feeling bad if we fall short of them and good if we live up to them.' In line with the above mentioned view, a comment from a lecturer demonstrated that she was happy when students rated her highly but noted the need to continue learning to teach: 'The evaluation in subject $\mathrm{X}$ was good. Out of 5 the rating was over 4 . I want to do more because I should never be 
complacent' (Gel). Her assertion of complacency was in line with what Archer (2003, p. 109) notes: 'emotions cannot be said to ensure satisfaction but are plans and readiness for ensuring satisfaction.' However, some lecturers were disappointed as the ratings did not reflect the effort invested into the course: 'in their feedback it was a bit interesting, they did not rate me very highly, I think the average was 3.5 out of 5 and I was a bit disappointed because I had put a lot of effort into it' (Neth). Thus, both positive and negative feedback elicited emotions.

Emotions were found to be central to the things that lecturers cared about most and to the act of caring itself. Human beings tend to feel joy or disappointment in their environment; however, the same emotions may prompt lecturers to learn to teach in cases where they effectively perform their job.

\section{Performative achievement as a concern}

In the practical order, the ultimate concern is performative achievement, that of easing one's task by making it efficient and effective. Performative achievement is key to lecturers' professional growth. Archer (2000) asserts the primacy of the practice in relation to the other orders.

Comments from most respondents showed that what they cared about most was their ability to teach well but stated it from the perspective of students' learning. The objective of their teaching approaches seemed to be, to enable students to develop knowledge, skills, and values. A comment from a lecturer demonstrated that building students' minds is what he perceived to be good performance:

For me, building people's minds is better than building a building, because when you build people's mind, you are touching on God's creatures and to me that is very valuable. What I found out is that as you teach, you are placed in a position to shape people's thinking in many dimensions. (Mij)

What the above lecturer seems to care about most is enabling students to grow in many facets of life. It could be acquisition of knowledge, skills, and values.

From the data, what five respondents cared about most in students' development was to inculcate values. One comment illustrated the value of character building: 'character is key to me, it is something that I hold onto' (Mao). She cared most about transforming students into orderly citizens:

When I see my students orderly in life whichever way - they are orderly, they respect themselves and others, they are more human than when they came, they are happier and they have confidence in themselves - then I know I have taught. (Mao)

Lecturers in this study cared about student learning and how well they performed their teaching task. They cared about changing students' attitudes towards their subjects, character building, and acquisition of knowledge and skills. This may have encouraged them to attend the ADPs.

Being and becoming an effective lecturer entails more than developing a personal identity as indicated in the above comments. Archer (2000) notes that simply to be a role incumbent has no such emotional implication. Lecturers who vest none of their self-worth in the result of their teaching are not downcast with student evaluation or 
failure, for example. Archer (2000, p. 219) argues that it is our definition of what constitutes self-worth that determines which normative evaluation matters enough for us to be emotional about.'

\section{Self-worth as a concern}

Twenty-three (92\%) lecturers felt that the learning in ADPs had played a role in their personal and professional growth. A comment from one lecturer illustrated how his identity had changed:

I used to be a traditional lecturer who goes and reads or just teaches the notes; how I understand them. But after ADP, my teaching became better. I engaged students more in their learning. (Bor)

In being and becoming good lecturers, Leibowitz, van Schalkwyk, Ruiters, Farmer, and Adendorff (2012) note that lecturers tend to be driven by the concern of their selfworth. Wenger (1999, p. 5) equates 'becoming' to 'identity' that is 'a way of talking about how learning changes who we are and creates personal histories of becoming in the context of our communities.' How lecturers are viewed by their students, the students' opinion and ratings, in a way illustrates their becoming.

One thing that I have loved in teaching and makes me feel that I can teach for a very long time is the joy of hearing the students say that I am a very good teacher. I have heard that many times I think that makes me feel good. (Daw)

Archer (2000) affirms that the most important of our social concerns is our self-worth. As earlier stated, it is our definition of what constitutes self-worth that determines which normative evaluation matters enough for us to be emotional about them. The above comment indicates that the students' definition of a good lecturer is one who relates theory to practice: 'they comment that he knows the industry very well. I feel like I know something I need to share with them and this is very important for me' (Daw).

Unlike personal identity, social identity is more about being public, for example, being a public expert in teaching or what Archer refers to as an actor. Archer maintains that it is only specific people who become 'actors' (Archer, 2003, p. 118). To achieve a social identity, actors go beyond being particular persons, for example having a personal identity of a lecturer, but find other roles such as a presenter at a conference or a consultant in which 'they feel they can invest themselves, that is, they personify the roles they choose to occupy' (Archer, 2000, p. 257). Whereas personal identity is achieved in the three orders - the natural, practical, and social - social identity is only achieved in the social order. Unlike personal identity, which is achieved by people such as lecturers with the same life opportunities, achieving social identity requires one's agency to mediate one's becoming an actor. In the comment below, the lecturer became socially significant due to her intentionality and reflexivity:

I was called to be a keynote speaker at teaching practice conference, the first teaching practice conference to be held by.... I was a keynote speaker. (Mao) 
Networking with colleagues makes lecturers socially significant in the eyes of colleagues. They become actors, that is, the lecturers play the role of being lecturers but go further and gain more roles in the social world.

An analysis of lecturers' agency in shaping their learning is considered integral as 'voices from below' need to be heard (Crawford, 2010, p. 189). Within an analysis of lecturers' formal and informal learning to teach, it is important for academic developers to note that ADPs may enable or constrain the ability of lecturers to exercise their emergent powers of intentionality and reflexivity to become better lecturers. However, to be effective, ADPs require the intelligent co-operation of agents (Archer, 2003).

\section{Conclusion and implications}

I have explained the variations in lecturers' courses of action by applying Archer's Realist Social Theory (Agency). Although the influence of ADPs may be monumental to lecturers' learning to teach, lecturers as individuals also contribute towards their learning. Lecturers have vested interest in improving students' learning and therefore are agents in higher education. The lecturers' agency mediates their learning through their actions in the workplace and this transforms practice. The theory provides us with a basis to explain the lecturers' learning to teach from a sociological perspective rather than psychological as indicated by Gibbs (2013).

Lecturers learn from many sources, but as individuals, they have a role to aggregate learning from various sources into a whole. They also have a role in establishing the kind of lecturer they want to become, their modus vivendi or a way of life. In addition, lecturers have different concerns. Whereas some lecturers are interested in becoming better teachers, others are motivated to become socially significant. Academic developers may want to keenly identify the kind of roles lecturers want to play and assist them in achieving them instead of providing one-size-fits-all approaches.

The use of personal emergent powers of intentionality and reflexivity in explaining the variation in lecturers' courses of action enables us to deepen the discourse on lecturers learning how to teach. The two emergent powers are internal to the lecturers, but empowering. The exercise of agency mediates the lecturers' contexts and the concerns. This leads to different courses of action that transform practice.

In this study, reflexive deliberations were essential in lecturers learning to teach. However, an in-depth study on how lecturers reflexively survey the three orders of reality - natural, social, and physical - and the types of reflexivity that assist lecturers to learn better in ADPs would add another perspective to explain lecturers learning how to teach.

\section{Disclosure statement}

No potential conflict of interest was reported by the author. 


\section{Notes on contributor}

Mary Omingo is an assistant director teaching and learning network at the Aga Khan University. Previously she was the director of teaching and learning at Strathmore University in Kenya. She is a founding member of the Association for Faculty Enrichment in Learning and Teaching (AFELT), in Kenya. She holds a $\mathrm{PhD}$ in higher education (curriculum studies) from Stellenbosch University, Cape Town, South Africa.

\section{References}

Archer, M. S. (1995). Realist social theory: The morphogenetic approach. Cambridge, UK: Cambridge University Press.

Archer, M. S. (2000). Being human: The problem of agency. Cambridge, UK: Cambridge University Press.

Archer, M. S. (2003). Structure, agency, and the internal conversation. Cambridge, UK: Cambridge University Press.

Archer, M. S. (2007). Making our way through the world: Human reflexivity and social mobility. Cambridge, UK: Cambridge University Press.

Archer, M. S. (2010). Routine, reflexivity and realism. Sociological Theory, 28(3), 272-303.

Bhaskar, R. (1998). Philosophy and scientific realism. In M. S. Archer (Ed.), Critical realism: Essential readings (pp. 16-47). London: Routledge.

Clegg, S. (2005). Theorizing the mundane: The significance of agency. International Studies in Sociology of Education, 15(2), 149-164.

Crawford, K. (2010). Influences on academics' approaches to development: Voices from below. International Journal for Academic Development, 15(3), 189-202.

Elder-Vass, D. (2010). The causal power of social structures: Emergence, structure and agency. Cambridge, UK: Cambridge University Press.

Gibbs, G. (2013). Reflections on the changing nature of educational development. International Journal for Academic Development, 18(1), 4-14.

Julien, H. (2008). Content analysis. In L. M. Given (Ed.), The Sage encyclopedia of qualitative research methods (pp. 120-121). Los Angeles, CA: Sage Publications.

Kahn, P. (2009a). Contexts for teaching and the exercise of agency in early-career academics: Perspectives from realist social theory. International Journal for Academic Development, 14(3), 197-207.

Kahn, P. (2009b). On establishing a modus vivendi: The exercise of agency in decisions to participate or not participate in higher education. London Review of Education, 7(3), 261-270.

Knight, P., Tait, J., \& Yorke, M. (2006). The professional learning of teachers in higher education. Studies in Higher Education, 31(3), 319-339.

Leibowitz, B., van Schalkwyk, S., Ruiters, J., Farmer, J., \& Adendorff, H. (2012). "It's been a wonderful life": Accounts of the interplay between structure and agency by "good" university teachers. Higher Education, 63(3), 353-365.

Maxwell, J. A. (2013) Qualitative research design: An interactive approach (3rd ed.). Applied social research methods. Thousand Oaks, CA: SAGE Publications.

Musholt, K. (2013). Self-consciousness and nonconceptual content. Philosophical Studies, 163(3), 649-672.

Quinn, L. (2012). Enabling and constraining conditions for academic development. In L. Quinn (Ed.), Re-imagining academic staff development: Spaces for disruption(pp. 27-50). Stellenbosch: SUN MeDia.

Rienties, B., \& Hosein, A. (2015). Unpacking (in)formal learning in an academic development programme: A mixed-method social network perspective. International Journal for Academic Development, 20(2), 163-177. 
Roxå, T., \& Mårtensson, K. (2015). Micro cultures and informal learning: A heuristic guiding analysis of conditions for informal learning in local higher education workplaces. International Journal for Academic Development, 20(2), 193-205.

Sayer, R. A. (2010). Method in social science: A realist approach (Rev. 2nd ed.). London: Routledge.

Vorster, J., \& Quinn, L. (2012). Theorizing the pedagogy of a formal programme for university lecturers. In L. Quinn (Ed.), Re-imagining academic staff development: Spaces for disruption (pp. 51-70). Stellenbosch: SUN MeDia.

Wenger, E. (1999). Communities of practice: Learning, meaning, and identity. Cambridge, UK: Cambridge University Press. 